\title{
PALAVRAS DE CRISTAL: SUJEITO, SENTIDO E VERSÕES NO PROCESSO DISCURSIVO DE REFORMULAÇÃO DE LIVROS
}

\author{
Adriana Pozzani de La Vielle e Silva*
}

Resumo: O campo teórico da Análise do Discurso sustenta a presente discussão sobre o processo discursivo de reformulação de livros. Ao focar o eixo sujeito-sentido-versões - com uma ênfase pontual nos mecanismos sócio-bistóricos constitutivos do trabalho de autoria -, buscamos explicitar o modo como o acontecimento enunciativo (INDURSKY, 2008), uma vez que é responsável pela emergência da chamada "edição revista", afeta o enunciável próprio a uma dada formação discursiva e reconfigura as redes de memória. O sujeito-autor, tomado na teia das contradiçoes históricas do campo em que se constitui, entra num jogo de repetir-deslocar-esquecer. A reflexão em pauta ganha um matiz a mais quando a identidade polêmica da "edição revista" entra em cena nos encaminhamentos finais.

Palavras-chave: Análise do Discurso. Autoria. Contradição.

\section{INTRODUÇÃO}

O processo discursivo de reformulação de livros, eleito objeto analítico de minha Dissertação de Mestrado - a saber: "Entretextualidade nas fronteiras do enunciável: um olhar sobre o processo discursivo de reformulação de livros" (cf. SILVA, 2009), orientada pela Profa. Dra. Freda Indursky (UFRGS) -, aqui se faz novamente objeto de reflexão, desta vez para um enfoque específico (tanto quanto breve) do eixo sujeito-sentido-versões, com ênfase pontual sobre o trabalho do sujeito em ressignificar termos e entretecer "novos" saberes. Interessa-nos capturar o sujeito na teia de contradições históricas em que ele se vê enredado, e fazê-lo a fim de explicitar o modo pelo qual o acontecimento enunciativo (INDURSKY, 2008), responsável pela emergência da chamada "edição revista", afeta o enunciável próprio a uma formação discursiva e instaura novas redes de memória.

\footnotetext{
PPG-Let/UFRGS; Mestre em Estudos da Linguagem; Email: adriana.vielle@yahoo.com.br.
} 
Investigaremos, pois, os modos subjetivos de apropriação, reprodução e transformação de saber que são colocados em cena pelo processo discursivo em questão, e o faremos com vistas a explicitar alguns mecanismos sócio-históricos atuantes na textualização de saberes. Analiticamente, buscaremos flagrar o encontro entre língua e conjuntura sócio-histórica, o qual só é possível em virtude de um sujeito que o promove no discurso, e que, aliás, faz isto ao ocupar um lugar discursivo que lhe permite fazer-se leitor de si e, em seguida, "reexercer" a funçãoautor. A discussão aqui proposta ganha um matiz a mais quando entra em cena a polêmica identidade da edição revista (ER), na relação que esta estabelece com a edição primeira ou, como temos dito, com a edição "de partida" (EP).

Courtine (2006, p. 27) propõe que se busquem "textos que incomodem", pelo fato de constituírem-se, de modo privilegiado, em espaços nos quais se joga com o equívoco, com a ruptura, com a desestabilização. Trata-se de encontrar textos que façam irromper a alteridade sobre o mesmo, que joguem com os sentidos, com a memória. E joguem ainda, como no presente caso, com a interdição de sentidos outros: sentidos anteriores, mas inevitavelmente coexistentes mesmo que sejam contraditórios; esquecidos talvez, mas jamais apagados, jamais destruídos. A nós interessa o "incômodo" de textos que, diante da irreversibilidade que lhes é inerente, somam-se àquilo que eram sem que possam isentar-se do inextricável fardo de um seu avesso; um avesso do qual é impossível se dissociar e apagar de si.

Posto o que precede, norteiam este artigo as seguintes questões: de que modo o trabalho do sujeito ressignifica saberes e costura entre si o mesmo e o diferente, afetando significativamente as redes de memória? Como o sujeito-autor-revisor se relaciona com as diferentes versões que produziu, em relação à "identidade" do livro? Em linhas gerais, é sobre isso que trata o presente artigo. Para reflexões mais aprofundadas, conferir Silva (2009). 


\section{A REFORMULAÇÃO DE LIVROS PENSADA DESDE O QUADRO TEÓRICO DA ANÁLISE DO DISCURSO}

Defendemos que a produção da chamada "edição revista" não resulta da vontade exclusiva (tal como um capricho) do sujeito, mas de um processo que implica uma rede sócio-histórica das práticas discursivas a corroborar a reconfiguração do saber, meio pelo qual a reformulação fomenta a continuidade de uma dada ciência.

Ao abordar a elaboração de conhecimentos científicos enquanto processo discursivo, Pêcheux ([1975] 1988) afirma que a produção histórica desses conhecimentos não resulta de um mero ato de inovar mentalidades ou de uma criação imaginativa do homem; ela é efeito de todo um processo histórico. Assim sendo, os conceitos de uma dada ciência não possuem exatamente um sentido, mas antes uma "função em um processo" ([1975] 1988, p. 193). Segundo Pêcheux, "vão se formando 'respostas' novas a questões que não haviam sido colocadas", processo esse no qual certos "nomes e expressões se apagam", ao passo que outros "aparecem sob o efeito de certos deslocamentos do campo, de certas intrusões 'incongruentes' de elementos 'lançados', desligadoscaídos de outros lugares" ([1975] 1988, p. 194). A produção de conhecimentos coloca em xeque a hipótese da objetividade científica, para Pêcheux. Afirma ele que: "O processo da produção dos conhecimentos está, pois, indissociavelmente ligado a uma luta a propósito de nomes e de expressões para aquilo que eles designam" [...] (PÊCHEUX, [1975] 1988 , p. 197, grifos nossos). E a "suposta indiferença" quanto a tais nomes não passa de mito.

No que concerne ao processo discursivo aqui tomado como objeto analítico, está-se lidando com práticas discursivas que têm por objetivo invalidar determinadas parcelas de saberes e posicionamentos a elas vinculados, proceder esse através do qual simultaneamente validam a legitimação de outras parcelas de saber e respectivas tomadas de posição. Está-se, enfim, diante da iminência de uma descontinuidade com certas práticas teórico-metodológicas vigentes até então em um dado campo X de conhecimentos. O texto da edição revista, tomado enquanto materialidade linguística dos discursos que a sustentam, revela, pela simbolização, a cisão da ideologia, ou, nos termos de Pêcheux (1990a), o fato de que a ideologia é "dividida" e "não idêntica a si mesma". No 
cerne da questão, algo elementar: a relação homem-saber ocorre via discurso, não sendo, portanto, nem direta, nem transparente, nem imutável. As contradições ideológicas, materializadas através dos comentários sobre as edições (na revista), atestam que os processos discursivos no interior dos quais se inscreve o "novo" discurso do sujeito são, eles mesmos, históricos, ou seja, mais amplos do que o faz pensar aquele estado específico das condições de produção que marcam o surgimento da nova edição.

Reprodução e transformação revelam-se indissociáveis no processo discursivo em exame, atravessando a produção e a reformulação do conhecimento, ou ainda, as práticas discursivas pelas quais se fazem circular novos saberes. Isso encontra o que afirma Pêcheux ([1983] 1990b, p. 56), para quem todo discurso, simplesmente pelo fato de existir, possibilita uma "desestruturação-reestruturação" das redes de memória, enfim, das filiações de sentido que se vão tecendo. Todo discurso - prossegue o autor - "é o índice potencial de uma agitação nas filiações sócio-históricas de identificação", e isto na medida em que ele é simultaneamente "um efeito dessas filiações e um trabalho (mais ou menos consciente, deliberado, construído ou não, mas de todo modo atravessado pelas determinações inconscientes) de deslocamento no seu espaço" ([1983] 1990b, p. 56, grifos nossos).

É exatamente isso o que ocorre no processo discursivo de reformulação de livros, visto que, num determinado momento, o texto de uma dada edição passa a já não servir, e até mesmo a ser inapropriado, daí decorrendo então a necessidade de "atualizar" o livro, de desestruturá-lo a fim de reestruturá-lo novamente, desta vez sob outras maneiras. Com isto, cria-se o confronto na hegemonia de saberes que perdem seu posto hierárquico em prol da hegemonia da "nova" parcela de saberes. Pensemos sobre essa questão a partir de Zandwais (2005, p. 84), que diz o seguinte: "Se não se pode julgar o espírito de uma época somente pelo que ela pensa de si mesma", visto que "cada época está impregnada de suas verdades, e, portanto, de suas formas de inclusão de saberes em torno de como se legitimam determinadas práticas sociais/discursivas em detrimento de outras", então é preciso, ao menos, apreender suas relações de contradição, a fim de que se possa investigar sob que condições dadas certos saberes "tornam-se hegemônicos ou legitimados superestruturalmente e passam a exercer 
determinadas formas de controle sobre outros." Cumpre, portanto, investigar essas práticas discursivas que instauram a contradição nas formações discursivas.

As formações discursivas (FDs) têm papel determinante em Análise do Discurso: é no interior delas que se constituem, simultaneamente, sujeito e sentido (no/pelo discurso). Defendendo que a literalidade é uma ilusão, Pêcheux ([1975] 1988) constrói uma perspectiva segundo a qual não existe uma relação de transparência que permitiria afirmar que uma determinada palavra possui um sentido intrínseco. Para esse autor, o sentido de uma formulação dada decorrerá das posições ideológicas em jogo no processo sócio-histórico em que ocorre a produção de tal formulação, posições essas que, por sua vez, se encontram vinculadas a formações discursivas específicas. Resulta daí, ainda de acordo com Pêcheux ([1983] 1990b), a equivocidade da língua: todo enunciado é passível de tornar-se outro ao deslocar-se discursivamente de seu sentido e derivar para outro, movimento esse que, para o referido autor, ocorre no momento em que o enunciado migra de uma FD a outra. No entanto, deve-se dizer que não é apenas a FD - enquanto um domínio específico de saber - que confere sentido àquilo que é dito, mas também a legitimação (ou não) do lugar a partir do qual o sujeito produz discurso. A FD regula o que pode/deve ou não ser dito na conjuntura dada da história de uma formação social, conjuntura essa caracterizada por certo estado das relações sociais e da produção de conhecimento.

Quando da interpelação, o sujeito apropria-se de saberes que provêm do interdiscurso. A tomada de posição, condição sine qua non da produção do discurso, ocorre através de alguma destas três modalidades: identificação, contraidentificação e desidentificação, todas envolvendo uma relação entre o sujeito e o Sujeito Universal (ou forma-sujeito, organizadora dos posicionamentos possíveis) da formação discursiva no interior do qual se constitui o sujeito. A primeira modalidade concebida por Pêcheux ([1975] 1988), a identificação, refere uma superposição entre sujeito e Sujeito; trata-se do "bom sujeito", aquele que reproduz fielmente os saberes. Já o segundo caso, contraidentificação, refere uma relação tensa entre sujeito e Sujeito, uma agitação (este é um termo bem apropriado) no interior da FD. Como o nome sugere, a contraidentificação corresponde a uma tomada de posição pela qual o 
sujeito, ainda que conteste e/ou questione parcelas de saber da FD, ainda permanece ali inscrito, sendo chamado por Pêcheux, em decorrência disso, de "mau sujeito". Essa permanência, aliás, atesta a não unicidade inerente à forma-sujeito. A contraidentificação permite entrever heterogeneidade na formação discursiva. A terceira e última modalidade é a desidentificação, em que o sujeito desliga-se de relações com o Sujeito Universal de um campo e migra para outra FD, movimento em que se identifica com novo Sujeito a partir de nova interpelação.

Indursky (2008), fazendo de tais considerações pêcheutianas a base de sua reflexão, propõe uma releitura dessas três modalidades, releitura essa decorrente do objetivo de refletir acerca da trajetória da categoria sujeito em AD. Indursky acredita que, antes de identificar-se com a forma-sujeito propriamente dita e através dela com a ideologia, o sujeito relaciona-se, na verdade, com parcelas de saber da FD. Para essa autora, o fato de a forma-sujeito ser fragmentada e comportar em si a contradição autoriza que se possa considerar a existência de mais do que duas posições possíveis: há uma posição que aparece como dominante, mas há também espaço não para uma, mas para várias outras posiçõessujeito "não dominantes" em relação àquela. Depreende-se, das reflexões tecidas por Indursky, a possibilidade de haver diferentes posicionamentos coexistentes de contraidentificação passíveis de ser comportados pela forma-sujeito de um campo de saber, e isto em decorrência de singulares modos de relação entre sujeito e ideologia (via tomada de posição). A questão para Indursky é pensar o caso em que a movimentação de sentidos no interior da FD não chega a induzir a ruptura "radical e definitiva", antagônica mesmo, própria à desidentificação. Daí a proposta de conceber o acontecimento enunciativo, que, relacionado à contraidentificação, coloca em cena um novo modo de enunciar no interior de uma FD, modo este que opera pelo viés da tensão e do estranhamento; trata-se, pois, de um conflito interno, que ocorre em relação aos modos enunciativos de uma dada posição-sujeito (geralmente a dominante).

O novo modo de enunciar, uma vez instaurado no domínio em que irrompe, atesta o atual posicionamento que o sujeito-autor-revisor passa a assumir. Tal assunção traz a possibilidade da produção de novos sentidos não só ao campo teórico, mas à materialidade da edição revista (já que esta o representa linguístico-historicamente). Neste caso, é 
preciso desconstruir a edição antiga e construir a nova versão do livro numa edição dita "revista", procedimento esse que coloca em cena a tensão simultânea entre aquilo que, parafraseado (ou reproduzido ipsis litteris) permanece na mesma matriz de sentido, e aquilo que, deslocado, implica efetivamente a reformulação, ou seja, um modo totalmente outro de enunciar. Indissociavelmente, as ilusões de que "isto é meu" e "eu digo (ou reformulo) isto desta forma" caracterizam o modo pelo qual o sujeito-autor-revisor é afetado pelo jogo entre memória e esquecimento, no momento em que o texto objeto de reformulação (a edição antiga) apresenta-se a ele enquanto um "acontecimento a ler" (PÊCHEUX, [1983] 1999).

Orlandi (2001, p. 65) afirma que as versões mostram "uma relação que não é rígida nem definitiva com as formações discursivas: as margens das diferentes versões exibem difíceis limites fluidos e cambiantes na relação das formações discursivas". Pode-se deslocar isto e dizer que revelam a heterogeneidade da forma-sujeito no âmbito de uma única FD. É inerente a todo texto, conforme a autora, a possibilidade de diferentes formulações e reformulações possíveis; há textos possíveis nas margens do texto. Ocorre que as diferentes versões de um texto não se dispersam isoladamente; ao contrário, formam redes de memória em relação àquilo que é dito novamente e reformulado. $\mathrm{O}$ novo livro, decorrente do processo de reformulação, constrói-se com base em já-ditos e situa-se em relação a um dado contexto sóciohistórico que, simultaneamente, induz, constitui, marca suas condições de produção. Isso conduz a abordar outra noção fundamental a esta reflexão: o conceito de memória.

$\mathrm{Na} \mathrm{AD}$, não se concebe a memória como algo de ordem cognitiva, mas sim em âmbito de um "tecido social", ou como "uma relação de discursos, ou seja, discursos dos universos do interdiscurso ressoam entre si formando a memória que nos permite produzir e ler" (MITTMANN, 2005, p. 249). E não se trata de ressoarem incondicionalmente, mas conforme o modo como são entrelaçados os mais diversos recortes interdiscursivos (através de singulares modos de textualização). Condição do legível em relação a si mesmo (PÊCHEUX, [1983] 1999), a memória é aquilo que vem, pois, restabelecer, na medida em que se tome o texto enquanto "acontecimento a ler", os mais variados tipos de "implícitos", apontados por Pêcheux ([1983] 1999, p. 
52) como os pré-construídos, elementos citados e relatados, discursostransversos, enfim, de que a leitura do texto em questão necessita. Assim, a memória é tecida através de uma trama de formulações (re)atualizadas sem cessar, as quais remetem às mais diversas formações discursivas e marcam, também, o ponto de encontro entre um "passado" e um "presente" da sequência considerada. A memória concerne, ainda, à existência histórica do enunciado no interior de práticas discursivas reguladas por aparelhos ideológicos (COURTINE, 1981). Há sempre encontro de uma memória com uma atualidade, e é nesse ponto que se instaura o efeito de memória, efeito este que, sendo "fortemente lacunar" (INDURSKY, 2003, p. 103), permite o deslizamento de sentidos, a deriva, enfim, a transformação, a ressignificação. Aqui deve ser mencionada a questão do esquecimento, indissociável da memória: se por um lado, o sujeito "esquece" sentidos outros e possibilidades de produzir distintamente seu discurso, por outro lado, para atribuir sentidos àquilo que lê, precisa mobilizar a memória discursiva. E este é, pode-se dizer, o paradoxo constitutivo da produção e reformulação de qualquer texto (no caso aqui em pauta, dos livros mobilizados).

A memória, para Orlandi (1996b), funciona com versões enunciativas; inscreve o discurso em filiações, "e o sentido que as representa está sempre sujeito a deslocamento". Nessa perspectiva, as distintas versões são efeito não apenas de relações de sentido (relação entre discursos), mas também de relações de força (relação de um discurso com a posição daquele que enuncia). No entanto, não é apenas a memória discursiva que atua no processo discursivo de reformulação de livros, mas igualmente aquela que Mariani (1998) designa como "memória social". Para a autora, esta memória social refere-se a "um processo histórico resultante de uma disputa de interpretações para os acontecimentos presentes ou já ocorridos", de modo que, como resultado desse processo, "ocorre a predominância de uma de tais interpretações e um (às vezes aparente) esquecimento das demais”. Segundo Mariani, "naturaliza-se, assim, um sentido 'comum' à sociedade" (ou, no caso que aqui nos mobiliza, podemos dizer: aos estudiosos de um domínio X), o que, no entanto, não significa "que o sentido predominante apague (anule) os demais", ou que esse sentido (ou esses sentidos) "não possa(m) vir a se modificar. Muitas vezes os sentidos 'esquecidos' funcionam como resíduos dentro do próprio sentido begemônico" (1998, p. 
34-35, grifos nossos). É precisamente essa disputa de interpretações, e tudo o que a ela concerne, que pretendemos trazer à tona.

\section{REPETIR, DESLOCAR, ESQUECER: O TRABALHO DE AUTORIA EM FOCO}

De acordo com Orlandi (1996b, p. 14), qualquer modificação na materialidade textual "corresponde a diferentes gestos de interpretação, compromisso com diferentes posições do sujeito, com diferentes formações discursivas [ou até com a mesma, enfatizamos], distintos recortes de memória, distintas relações com a exterioridade". É de modificações na materialidade discursiva (modificações linguísticohistóricas, portanto) que se tratará a seguir. A leitura comparativa das edições traz logo à tona confrontos de sentidos, e tais confrontos não são outra coisa senão um atestado de que mudaram não só as formas de os sujeitos-autores relacionarem-se com a ideologia, mas a própria conjuntura que marca a produção de conhecimentos. Justificada a existência da edição revista (por meio de prefácio e/ou nota do Autor), o restante do texto flui então sob a ilusão da homogeneidade. É esta impressão de que o texto corresponde a um todo homogêneo (ou seja, o "efeito-texto") que será examinada abaixo. O fato em pauta é o de que, ao explicitar a ocorrência da reformulação, a edição revista abre espaço à deriva de sentidos resultantes de outras relações entre sujeito, língua e história: há outros sentidos em algum lugar, no caso em questão, na EP. Senão vejamos.

\subsection{A reformulação e a movimentação dos sentidos nas ressignificações}

A repetição de uma palavra ou de um enunciado não precisa ser necessariamente ipsis litteris, nem mesmo parafrástica; ela pode, também, ser uma repetição ressignificada, como é o caso que aqui nos interessa ${ }^{1}$.

\footnotetext{
${ }^{1}$ Num gesto metodológico, optamos por deixar de lado a modalidade meramente parafrástica de reformulação, e isto por entender que, no contexto específico da presente reflexão, ela pouco nos diria acerca da efetiva movimentação de saberes efetuada no interior de um dado campo de conhecimento.
} 
É com esse argumento que justificamos o fato de que uma categoria ou enunciado presente na EP retorna na ER sendo, ao mesmo tempo, ele mesmo e um outro. $O$ presente recorte permite abordar os deslocamentos de sentido, pelos quais um determinado termo ou enunciado, uma vez ressignificado, torna-se outro sem deixar de ser, formalmente, o mesmo. Estamos, pois, diante de processos polissêmicos, que permitem a uma mesma forma material significar, na ER, algo diferente daquilo que significava na EP. Uma observação, no entanto, que se revela essencial e deve ser enunciada desde já, consiste no fato de que, tomada a especificidade de nosso objeto de investigação, a polissemia não implica obrigatoriamente a mudança de formação discursiva; ora, essa mudança inexiste no processo discursivo que temos examinado. Porém, de que chamaríamos o deslocamento de sentidos senão de polissêmico? Vejamos algumas sequências discursivas, advertindo, antes, que adotamos as notações EP para "edição de partida" e ER para "edição revista":

(SD1) EP - Não somos partidários de pôr epígrafes nem títulos nas diversas partes do trabalho. Contudo, não bá inconveniente em colocá-los. (CARRETER; LARA, 1962, p. 67, grifos nossos)

ER - Não somos partidários de pôr epígrafes nem títulos nas diversas partes do trabalho. Isto pode prejudicar a unidade da redação. (CARRETER; LARA, 1963, p. 67, grifos nossos)

(SD2) EP - Acreditamos que a noção de enredo é clara, para todos, pois seu uso é comum quando se faz referência ao 'enredo de um filme ou de um romance'. [...] De agora em diante, vamos chamar assunto o enredo de um texto. (CARRETER; LARA, 1962, p. 30, itálicos nossos)

ER - Acreditamos que a noção de assunto é clara, para todos, pois seu uso é comum quando se faz referência ao 'assunto de um filme ou de um romance'. [...] De agora em diante, vamos chamar assunto ao resumo de um texto. (CARRETER; LARA, 1963, p. 30, itálicos nossos) 
(SD3) EP - Substantivo é o nome com que designamos seres em geral pessoas, animais e coisas. (BECHARA, 1987, p. 73, grifo do autor)

ER - Substantivo - é a classe de lexema que se caracteriza por significar o que convencionalmente chamamos objetos substantivos, isto é, em primeiro lugar, substâncias (homem, casa, livro) e, em segundo lugar, quaisquer outros objetos mentalmente apreendidos como substâncias, quais sejam: qualidades (bondade, brancura), estados (saúde, doença), processos (chegada, entrega, aceitação). (BECHARA, 2005, p. 112 , grifos do autor)

Tome-se inicialmente a SD1, extraída do par de edições (1962; 1963) do Manual de explicação de textos, de Carreter e Lara. Com base nos parágrafos precedentes, há que se convir que, nessa SD, "Não somos partidários de pôr epígrafes nem títulos nas diversas partes do trabalho" significa diferentemente na EP e na ER; aliás, os posicionamentos que marcam sua enunciação são divergentes. $\mathrm{Na} \mathrm{EP}$, há um vacilo pelo qual o sujeito-autor-revisor, embora não concorde com a colocação de epígrafes, abre espaço à concessão, por meio da formulação sucessora, aquela que inicia com "Contudo, não há inconveniente em colocá-los". Já na ER, a discordância é radical: no processo de reformulação, o sujeito-autor-revisor fecha aquele espaço da concessão, reafirmando sua discordância na formulação que sucede "Não somos partidários...", qual seja, "Isto pode prejudicar a unidade da redação". O enunciado "Não somos partidários..." tornou-se outro, é verdade, devido a um novo posicionamento do sujeito-autor; porém, evidentemente, tal posicionamento não é assim tão significativo ao domínio de saber como um todo. Outro caso, em que o posicionamento de fato o é, será abordado mais adiante.

É também das edições do Manual de explicação de textos que se extraíram as formulações que compõem a SD2. Comparando-se as formulações de cada edição, vê-se o trabalho do sujeito-autor-revisor em promover deslizamentos de sentido: assim, a palavra "enredo" desliza para "assunto", e esta, por sua vez, desliza para "resumo". Houve ressignificação, pois o sujeito-autor-revisor, ao reformular o texto da EP em condições de produção outras, atribuiu novos sentidos aos termos em pauta. Como se pode ali constatar, não é possível que haja um 
vínculo natural e, logo, imutável entre forma e sentido, porque se assim fosse, seria de fato impossível reconstruir teoricamente as categorias referidas como resumo, assunto, enredo. A possibilidade de fazê-lo, porém, coloca a necessidade de resgatar aqui algumas considerações de Pêcheux ([1975] 1988). Este autor afirma que uma palavra (ou uma proposição) é passível de significar de maneiras distintas conforme mude de FD, e que a equivocidade ([1983] 1990b) consiste justamente nesse deslocamento pelo qual um enunciado é passível de deslocar-se discursivamente de seu sentido a fim de derivar para um outro. Para Pêcheux ([1975] 1988), se o sentido não existe "em si mesmo"; isso permite enunciar que "as palavras, expressões, proposições etc. mudam de sentido segundo as posições sustentadas por aqueles que as empregam, o que quer dizer que elas adquirem seu sentido em referência a essas posições" ([1975] 1988, p. 160, grifos do autor), ou seja, em referência às formações ideológicas nas quais se inscrevem tais posições.

O caso do processo discursivo de reformulação de livros, porém, é um tanto distinto: ao fazer-nos ver palavras e enunciados que significam de outro modo sem que para isto mudem de domínio, autoriza a dizer que a equivocidade não precisa necessariamente envolver duas FDs; ela pode ocorrer no interior de uma única, a qual, sendo heterogênea, permite que o sentido mude porque, num movimento conjunto, mudou o posicionamento ideológico do sujeito enunciador (ora, ambos, sujeito e sentido, constituem-se juntos no discurso). Pela equivocidade - a possibilidade de que o sentido sempre possa ser outro (e ele, de fato, era!) -, a dispersão se inscreve no interior do que está sendo dito. Segundo Lagazzi-Rodrigues (2006, p. 84), "discutir a equivocidade é abrir espaço para tornar visível a contradição de diferentes interpretações", e é também "se expor às diferentes formas significantes" e, em se tratando da linguagem verbal, "expor-se às palavras".

Avançando na análise, vemos que a SD3 expressa alterações operadas em virtude de novos saberes até então inexistentes que passam a figurar na FD Gramática. Composta por formulações extraídas da Moderna gramática portuguesa, de Bechara (1987; 2005), essa SD permite constatar as mudanças significativas ocorridas na maneira de conceituar a categoria substantivo: "Substantivo é o nome com que designamos seres em geral - pessoas, animais e coisas” (EP). Passa-se, na edição revista, a 
definir substantivo como referente à "classe de lexema que se caracteriza por significar o que convencionalmente chamamos objetos substantivos, isto é, em primeiro lugar, substâncias (homem, casa, livro) e, em segundo lugar, quaisquer outros objetos mentalmente apreendidos como substâncias". É interessante notar a exclusão feita, na ER, da clássica referência aos "seres" (referência esta presente na EP), e, sobretudo, a incorporação de novos termos, tais como objetos substantivos e lexema.

Como se vê a partir do exame das SDs que compõem o presente recorte sobre o caso das ressignificações, há um sentido historicamente "sedimentado" (ORLANDI, 1996a), daí seu inicial estatuto dominante, mas o trabalho do sujeito-autor-revisor opera justamente sobre esse sentido, deslocando-o de sua hegemonia, desfazendo sua sedimentação, transferindo-o para outro lugar: o lugar do suposto apagamento (apagamento este que não é outra coisa senão esquecimento, visto que o sentido não desaparece totalmente: ele pode sumir da nova edição, mas não o faz quanto ao domínio de memória do "novo" livro). Em outros termos: com o gesto de ressignificar, o sujeito-autor-revisor imprime um novo sentido a uma dada categoria, sentido esse que emerge, portanto, como um "novo" sentido evidente, e isto em virtude do funcionamento da ideologia.

É interessante notar que a ressignificação de uma categoria como substantivo (cf. SD3), por exemplo, fará com que, uma vez tomada a coexistência das duas edições, se tenham duas respostas bem distintas à questão "O que se pode definir como sendo substantivo em Português?". No entanto, uma palavra $\mathrm{X}$, ou mesmo um enunciado $\mathrm{Y}$, não significa só o que lhe é atribuído na ER, mas também o que lhe havia sido atribuído na EP: assim, o sentido na EP, sendo residual, ressoa pela memória discursiva, em cuja rede de formulações se inscreve cada sequência analisada. Se no caso aqui tematizado o diferente emerge sob a mesma forma, veremos, a seguir, que ele pode aparecer de modo ainda mais radical: costurado aos saberes cuja reprodução é ainda autorizada. O próximo recorte, portanto, procura revelar a emergência de "novos" saberes. 


\subsection{A reformulação e o entretecer do diferente}

Observe-se a seguinte sequência discursiva de referência:

(SD4) EP - Pelo fato de haver escritura e não mais somente leitura, a crítica diz algo que a obra estudada não diz, mesmo que pretenda dizer a mesma coisa. Pelo fato de elaborar um novo livro, a crítica suprime aquele de que fala./Há graus nessa transgressão da imanência./No caso da descrição, o objeto de estudo é esta ou aquela obra literária particular; o objetivo é permanecer tão próximo quanto possivel da obra propriamente dita. (TODOROV , 1970, p. 13, grifos nossos)

ER - Pelo fato de haver escritura e não mais somente leitura, o crítico diz algo que a obra estudada não diz, mesmo que pretenda dizer a mesma coisa. Pelo fato de elaborar um novo livro, o crítico suprime aquele de que fala./ O que não quer dizer que essa transgressão da imanência não tenha graus./Um dos sonhos do Positivismo em Ciências Humanas é a distinção, ou seja, a oposição entre interpretação - subjetiva, vulnerável, enfim, arbitrária - e descrição, atividade certa e definitiva. Desde o século XIX, formularam-se projetos de uma "crítica cientifica" que, tendo banido toda "interpretação", não seria mais que pura "descrição" das obras. [...] (TODOROV, 1976, p. 12-13, grifos nossos)

A SD4, extraída do primeiro capítulo em ambas as edições de Estruturalismo e poética, de Todorov, permite refletir, inicialmente, sobre a questão pessoa/instituição, na medida em que se tome como ponto de partida a mudança de "a crítica" (EP) para "o crítico" (ER). Vê-se um deslocamento do geral, qual seja, a crítica enquanto coletividade, para o mais ou menos específico, a saber, o crítico enquanto um sujeito institucionalmente inserido; aliás, neste caso, um sujeito ocupante de um lugar discursivo que lhe permite enunciar um posicionamento $\mathrm{X}$ em relação a um livro Y. Observando-se, na $\mathrm{SD} 4$, a amplitude que não fazemos mais do que esboçar, vê-se a inserção de reflexões sobre o Positivismo, reflexões estas que não figuram na edição anterior, visto que ali não havia a preocupação em construir grandes explanações sobre interpretação. Ora, a edição de 1970 (EP) focaliza basicamente a descrição, ao passo que a de 1976 (ER), enfatizando a interpretação, traz em sua materialidade textual os novos saberes costurados por meio de

VIELLE e SILVA - Palavras de cristal... 
um gancho feito com o que estava sendo dito sobre interpretação; vejase: "Um dos sonhos do Positivismo em Ciências Humanas é a distinção, ou seja, a oposição entre interpretação - subjetiva, vulnerável, enfim, arbitrária - e descrição, atividade certa e definitiva.". A partir daqui, são inseridas considerações em torno da relação entre ciência, interpretação, obra literária e Poética, numa busca por esclarecer o objeto e o método próprios a este domínio de saber.

Constatar na ER o diferente entrelaçado àquilo que da EP se repete, normalmente exige comparar longos trechos; mas, ao longo da análise que efetuamos até aqui, buscamos sequências que, apesar de serem "mais breves", possibilitassem ver a emergência de saberes ausentes da edição de partida. A partir do domínio de memória de cada sequência - definido por Courtine (1982, p. 254) como uma "pluralidade contraditória" de sequências discursivas -, podem ser analisadas relações entre a produção da formulação e as repetições e rupturas colocadas em cena. Nessa perspectiva, a edição de partida (EP), propriamente, não chega a atingir uma dimensão interdiscursiva; ela não figura, em relação à edição revista, enquanto um saber da ordem do anonimato, do "ça parle" (PÊCHEUX, [1975] 1988). Já os novos saberes entretecidos na ER, na medida em que implicam o "todo complexo de FDs" ([1975] 1988), esses têm, de fato, procedência interdiscursiva. Se se observar o funcionamento do processo discursivo em exame, ver-se-á que, de um lado, existe a "volta" de um saber aparentemente estabilizado (o repetível), e, de outro, há uma descontinuidade a desestabilizar certas filiações de sentidos, em prol de filiações novas e totalmente distintas. Trata-se, neste caso, de uma reformulação que vem desfazer a série parafrástica, proceder este feito a partir de rupturas intradiscursivas em pontos isolados, tais como aqueles que grifamos.

\subsection{Entre a memória e o esquecimento}

Dado que todas as SDs observadas nas seções/subseções anteriores são afetadas pelo jogo entre memória e esquecimento, o fato de distribuí-las em blocos distintos não teve outro propósito senão o meramente didático: a análise seria mais clara se enfatizássemos, a cada seção, um dado aspecto do funcionamento do processo discursivo de 
reformulação de livros. Além disso, se, por um lado, é incontestável que os textos das edições tornam-se de fato muito diferentes entre si, por outro, devemos lembrar que, antes de tudo, eles correspondem a distintas versões que o sujeito produz de um livro seu.

A superfície textual da ER, por si só, não permite entrever a separação entre "mesmo" e "outro": a costura entre estes é perfeita, homogênea, resultante do trabalho de textualização efetuado pelo sujeito-autor-revisor. Lembre-se Indursky (2001), para quem esse trabalho, ao promover a ilusão de homogeneidade da superfície textual, faz emergir o "efeito-texto", pelo qual se cria a impressão de que tudo o que havia de ser dito (diríamos: reformulado) efetivamente o foi por um sujeito suposto como origem daquilo que se apresenta como "seu texto", ou, no caso, como edições de "seu livro". O trabalho do sujeito, portanto, reconstrói de tal modo a nova edição, que diferenças e semelhanças com a anterior só são perceptíveis, se não por cotejo direto, então via memória discursiva, uma vez que, na materialidade linguística, a sintaxe encarrega-se de apagar perfeitamente os vestígios do avesso textual da edição revista, qual seja esse avesso: a edição de partida. A escrita da ER é atravessada por ecos da EP: a edição anterior emerge e atesta memorialmente a exterioridade constitutiva da edição revista.

Avançando, ao tomar-se a proposta de Courtine $(1981 ; 1982)$ de analisar uma FD considerando o ponto de encontro entre os eixos intere intradiscursivos - como, na verdade, foi feito -, ver-se-á que EP não pode ser referida como inscrita no interdiscurso, pois implica saberes que, de uma forma ou de outra (repetidos ou modificados), ainda se inscrevem no mesmo domínio da ER. Tais saberes não chegam a "perder-se" no anonimato interdiscursivo, e sim prosseguem na materialidade, seja por um eco memorial, seja pela sintagmatização. Ora, resulta daí pensar as contradições históricas que o processo discursivo em exame possibilita entrever: não há contradição no interdiscurso, logo, não podemos afirmar que EP, uma vez "substituída" por uma nova edição, a ele retorne. Se pode haver alguma contradição, é antes no modo como o interdiscurso ressoa na linearidade intradiscursiva, e esse modo não remete a outra coisa senão à memória.

Vemos, ainda, que funciona não só a memória discursiva, mas, igualmente, a memória social (da qual fala Mariani, 1998), na medida em que os sentidos, implicando a inscrição em todo um processo sócio- 
histórico, confrontam-se na disputa de interpretações, disputa essa trazida por um procedimento - a reformulação - cuja análise permite entrever que os sentidos da EP figuram na ER enquanto residuais. Como acreditamos já ter pontuado até o momento, enfatizar o papel do domínio de memória não sugere que, no processo discursivo em exame, não haja também interdiscursividade.

Por fim, cabe apontar que, dado o estatuto memorial da edição de partida, a análise do processo discursivo de reformulação de livros viabiliza refletir acerca da constituição da memória histórica dos campos de conhecimento. Ainda que esse não tenha sido propriamente o foco desta reflexão, nem por isso se deixou de tangenciá-lo: ao abordarem-se os processos históricos de (re)constituição de domínios de saber, bem como as transformações internas pelas quais passaram certas formações discursivas (em especial, Gramática, Literatura e Poética), pôde-se entrever o papel do acontecimento enunciativo nas disputas interpretativas que foram, são e ainda irão se constituindo a cada novo contato de um dado campo com outros.

\section{ENCAMINHAMENTOS FINAIS SOBRE O PROCESSO DISCURSIVO EM PAUTA: A RELAÇÃO ENTRE VERSÕES}

O processo discursivo aqui tomado como objeto comporta constitutivamente em seu funcionamento a sucessão, a simultaneidade e a permanência. Há uma dialética entre, de um lado, a sucessão de certos saberes e tomadas de posição (os quais perdem seu posto em prol da hegemonia de saberes e posicionamentos emergentes), e, de outro, a simultaneidade de sentidos, logo, também dos posicionamentos que os instauram. Tal dialética converge em direção à permanência típica da ordem do discurso. Ora, segundo Pêcheux ([1969] 1993), todo discurso é parte de um processo discursivo contínuo e mais amplo. Há, portanto, um processo único (qual seja, a própria ordem do discurso) no interior do qual se inscrevem, em diferentes condições sócio-históricas, EP e ER.

A ordem do discurso é em si mesma inapreensível e só pode ser tomada através de objetos simbólicos (os livros, no caso) que, ao recortarem-na sócio-historicamente e materializarem-na linguisticamente, a trazem como um elemento constitutivo de sua própria existência. 
Nessa perspectiva, não são propriamente as edições que se sucedem (aliás, elas coexistem, apesar da ilusão de que uma invalida a outra); o que ocorre é a sucessão de uma dada relação "sujeito-saber-ideologia na conjuntura X" por uma outra relação "sujeito-saber-ideologia na conjuntura Y". Diante disso, a permanência assegura a reprodução do "mesmo", enfim, sua repetição, pois mudar totalmente os saberes seria trocá-los de formação discursiva, o que é inconcebível, pois se ocorresse, estar-se-ia diante da desidentificação própria a uma ruptura epistemológica (PÊCHEUX, [1975] 1988), e não de um redimensionamento interno (reformulação teórica). É por haver ainda algo de permanente - o repetível - que podem surgir diferentes modos de enunciar, sem que com isto se desfigure a relação do sujeito com o domínio de saber. A descontinuidade com certos modos de enunciar, por sua vez, instaurada pela sucessão acima referida, sinaliza a dispersão pelo jogo entre memória e esquecimento.

Tomado na teia das contradições históricas do campo em que se constitui, o sujeito entra num jogo de repetir/deslocar/esquecer, procedimentos estes aos quais cabe a metáfora topológica do nó, já que eles formam um verdadeiro nó na materialidade textual da edição revista. Considerar a contradição, instaurada no interior de um campo pelo viés da contraidentificação subjetiva, abre espaço para a emergência do outro, paradoxalmente mostrado e escondido sob a materialidade da edição revista. À moda do episódio de Clémentis - como Courtine ([1982] 1999) resgata de Kundera -, por meio do qual Clémentis, ainda que apagado da fotografia, faz-se nesta ainda presente memorial e materialmente através de seu chapéu, que emprestara a Gottwald, da mesma forma a edição de partida faz-se assim presente apesar da pretensão de que possa ser apagada em prol da edição revista. Nesta, aquela se mostra presente, mas transformada; ou ainda, presente pela necessidade de que se a esqueça: deve-se trazê-la à tona para enunciar que já não funciona mais como algo que "faz sentido ser publicado e academicamente mencionado"; enfim, para justificar, antes da substituição, a diferença e a primazia da nova.

Pensando-se o papel específico da ideologia no processo discursivo examinado, pode-se enunciar que: a) ela atua não tanto sobre a falta, quanto notadamente sobre a hipótese de completude. A esta ilusão vincula-se o efeito de que aquilo que devia ser modificado o foi, e 
tudo aquilo que deveria ser dito agora, igualmente o foi; b) ela atua, também, na circulação de saberes, pela divisão desigual das parcelas dos mesmos; e c) atua, ainda, na (re)produção/transformação de parcelas de saber, pelo sujeito-autor-revisor, na medida em que ela (a ideologia) funciona gerenciando os processos de (res)significação. Mas não o faz de modo homogêneo, nem como mentalidade de época, enfim, não se trata de um Zeitgeist (PÊCHEUX, [1975] 1988); a ideologia não é um a priori, mas o próprio cerne da contradição.

O ponto essencial que autoriza a referir o processo discursivo de reformulação de livros como radicalmente contraditório reside em que não se trata de opor uma edição $\mathrm{X}$ à sua edição revista $\mathrm{Y}$, mas de fazer equivaler, como semelhantes de modo geral (ou seja, no "pensamento diretor"), duas edições internamente distintas. A forma (título) permanece materialmente repetida; porém, seu sentido é outro e, por isso, defendemos que o livro é outro. Tomemos um exemplo: Moderna gramática portuguesa. O que significa Moderna em 1987 já não vale para 2005. Tampouco gramática tem sentido fixo diante dos avanços dos estudos linguísticos. Por trás da repetição aparentemente transparente do título, esconde-se a opacidade do discurso; o confronto entre enunciável e não-mais-enunciável; o fantasma do outro a espreitar o um; a errância de sentidos deslizantes-desviados-esquecidos. Esquecimento imbuído de memória.

Tudo quanto precede atesta/justifica nossa crença em que não há possibilidade de enunciar que os livros sejam efetivamente equivalentes, mas, isto sim, se pode e se deve pontuar sua irrepetibilidade. Ora, reforça isto o fato de as condições de produção de cada uma das edições serem singulares, logo, irrepetíveis.

\section{PARA FINALIZAR}

Importando-nos o como se diz enquanto ponto de partida para a compreensão do funcionamento da autoria em nosso objeto de reflexão, tivemos o propósito de examinar os modos de (re)textualização de saberes (apropriação, reprodução e transformação), visando a explicitar alguns mecanismos sócio-históricos em jogo na constituição simultânea de sujeito e sentido (ORLANDI, 1996a) quando da reformulação. 
Mesmo situado no interior do confronto entre o que podia/devia ser dito antes e aquilo que pode/deve ser dito agora, o sujeito procura construir uma unidade de sentido fechada, da qual os sentidos possam emergir como evidentes, como se não houvessem sido outros. Se, por um lado, a homogeneidade ilusória da ER emerge enquanto condição sine qua non de sua leitura, por outro, a análise viabilizou mostrar que a palavra denuncia a equivocidade do sentido; o discurso, a heterogeneidade da formação discursiva; e o novo posicionamento do sujeito, a cisão da ideologia. O novo livro desconstrói a unidade aparente da edição de partida, e ao fazê-lo atestando a incompletude dessa, acaba por acentuar a sua própria. Referir a reformulação enquanto processo discursivo autorizou a inscrever a edição revista, assim como a edição de partida, na historicidade da ordem do discurso e, desse modo, pensar os redimensionamentos internos de domínios de saber. Nessa direção, o acontecimento enunciativo (INDURSKY, 2008), do qual resulta a edição revista, não só fomenta a continuidade do campo de conhecimento no interior do qual surge, mas, sobretudo, instaura novas filiações de sentido e, com isso, reconfigura as redes de memória, fazendo trabalhar as fronteiras do enunciável de uma dada formação discursiva. Pôde-se, pois, entrever através de análise o papel desse acontecimento nas disputas interpretativas das quais a edição revista é o palco privilegiado... até que ela se torne uma edição de partida e também figure no memorial de uma outra edição. A produção de conhecimento, sendo parte de um processo discursivo mais amplo, existe em constante mutação, prova incontestável de que, antes de outra coisa, ela envolve sujeitos e prática de linguagem, enfim, palavras em movimento, discursos.

Diante de tudo o que foi construído aqui, impõe-se reconhecer o processo discursivo de reformulação de livros como uma reorganização essencial e constitutiva de todo trabalho de produção/reprodução/transformação de conhecimentos efetuado por um sujeito que não realiza essa tarefa sozinho, mas inserido numa conjuntura sócio-histórica que engendra e corrobora suas práticas discursivas. 


\section{REFERÊNCIAS}

COURTINE, J.-J. Quelques problèmes théoriques et méthodologiques en analyse du discours, Langages, Paris, n. 62, p. 9-127, juin 1981.

Définition d'orientations théoriques et construction de procédures en analyse du discours. Philosophiques, Paris, v. IX, n.2, p. 239-264, Octobre 1982.

. O chapéu de Clémentis. Trad. por Marne R. Rodrigues. In: INDURSKY, F.; LEANDRO FERREIRA, M.C. (Orgs.). Os múltiplos territórios da Análise do Discurso. Porto Alegre: Sagra-Luzzatto, 1999. p.1522. (Trad. de: La toque de Clémentis, 1982)

Metamorfoses do discurso político - Derivas da fala pública. Org. e trad. por Carlos Piovesani Filho e Nilton Milanez. São Carlos: Claraluz, 2006.

INDURSKY, F. Da heterogeneidade do discurso à heterogeneidade do texto e suas implicações no processo da leitura. In: ERNST-PEREIRA, A.; FUNCK, S.B. (Orgs.). A leitura e a escrita como práticas discursivas. Pelotas: Educat, 2001. p.27-42.

. Lula lá: estrutura e acontecimento. Organon - Discurso, língua, memória. Porto Alegre, v.17, n.35, p. 101-121, 2003.

. Unicidade, desdobramento, fragmentação: a trajetória da noção de sujeito em Análise do Discurso. In: MITTMANN, S.; CAZARIN, E.; GRIGOLETTO, E. (Orgs.). Práticas discursivas e identitárias - Sujeito e língua. Porto Alegre: UFRGS, 2008. p. 9-33.

LAGAZZI-RODRIGUES, S. Texto e autoria. In: . ORLANDI, E.P. (Orgs.) Discurso e Textualidade. Campinas: Pontes, 2006. p.81-103.

MARIANI, B. O PCB e a Imprensa - Os comunistas no imaginário dos jornais (1922-1989). Campinas: Unicamp; Rio de Janeiro: Renavan, 1998.

MITTMANN, S. Apresentação do texto Lecture et Mémoire: projet de recherche. In: INDURSKY, F.; LEANDRO FERREIRA, M.C. (Orgs.). Michel Pêcheux e a análise do discurso: uma relação de nunca acabar. São Carlos: Claraluz, 2005. p. 245-250.

ORLANDI, E. P. A linguagem e seu funcionamento: as formas do discurso. 4. ed. Campinas: Pontes, 1996 .

Interpretação: autoria, leitura e efeitos do trabalho simbólico.

Petrópolis: Vozes, 1996b. 
Pontes, 2001.

Discurso e texto - Formulação e circulação dos sentidos. Campinas:

PÊCHEUX, M. Semântica e discurso: uma crítica à afirmação do óbvio. Trad. por Eni P. Orlandi [et al.]. Campinas: Unicamp, 1988. (Orig.: Les vérités de la Palice, 1975)

Remontons de Foucault à Spinoza. In: MALDIDIER, D.

L'inquiétude du discours - textes de Michel Pêcheux. Paris: Éditions des Cendres, 1990a. p. 245-260.

O discurso: estrutura ou acontecimento. Tradução de Eni P. Orlandi. Campinas: Pontes, 1990b. (Orig.: Discourse: structure or event?, 1983)

. Análise automática do discurso. Trad. por Eni P. Orlandi. In: GADET, F.; HAK, T. (Orgs.). Por uma análise automática do discurso: uma introdução à obra de Michel Pêcheux. 2.ed. Campinas: Unicamp, 1993. p. 61161. (Tradução de: Analyse automatique du discours, 1969)

. Papel da memória. In: ACHARD, P. [et al.]. Papel da memória. Trad. e introd. de José H. Nunes. Campinas: Pontes, 1999. p. 49-57. (Tradução de: Rôle de la mémoire, 1983)

SILVA, A. P. L. V. Entretextualidade nas fronteiras do enunciável: um olhar sobre o processo discursivo de reformulação de livros. 2009. $144 \mathrm{f}$. Dissertação (Mestrado em Estudos da Linguagem) - Curso de Pós-graduação em Letras, Universidade Federal do Rio Grande do Sul, Porto Alegre, 2009.

ZANDWAIS, A. Relações entre a filosofia da práxis e a filosofia da linguagem sob a ótica de Mikhail Bakhtin: um discurso fundador. In: - (Org.).

Mikhail Bakhtin - Contribuições para a filosofia da linguagem e estudos discursivos. Porto Alegre: Sagra-Luzzatto, 2005. p. 83-100. (Col. Ensaios, v.20)

\section{REFERÊNCIAS DO CORPUS}

BECHARA, E. Moderna gramática portuguesa. 31. ed. São Paulo: Companhia Editora Nacional, 1987.

Moderna gramática portuguesa. 37. ed. rev. e ampl., 15. reimpr. Rio de Janeiro: Lucerna, 2005.

CARRETER, F. L.; LARA, C. Manual de explicação de textos - Cursos Médio e Superior. São Paulo: Centro Universitário, 1962. 
Manual de explicação de textos - Cursos Médio e Superior. 2. ed. rev. São Paulo: Centro Universitário, 1963.

TODOROV, T. Estruturalismo e poética. Tradução de José P. Paes. São Paulo: Cultrix, 1970.

Estruturalismo e poética. 4. ed. rev. e ampl. cf. ed. franc. de 1973. Tradução de José P. Paes e Frederico P. de Barros. São Paulo: Cultrix, 1976.

Recebido em 27/03/09. Aprovado em 10/08/09.

Title: Crystal words: subject, meaning and versions in the discursive process of books reformulation Author: Adriana Pozzani de La Vielle e Silva

Abstract: The theoretical field of Discourse Analysis stands at the basis of the present discussion on the discursive process for reformulation of books. By focusing on the axis subject-meaning-versions - with a punctual emphasis on the socio-bistorical mechanisms, which constitute the work of authorship-, here one tries to make explicit how the enunciative event (INDURSKY, 2008), once it is responsible for the emergence of the so called "revised edition," affects the enunciable proper to a certain discursive formation, and reconfigures the memory networks. The subject-author, caught within the web of historical contradictions in which be constitutes bimself, enters in a play of repeat-dislocate-forget. The reflection bere developed acquires an overtone when the polemical identity of the "revised edition" is dealt with at the final considerations.

Keywords: Discourse Analysis. Authorship. Contradiction. 